Check for updates

New York

Cite this as: BMJ 2021;374:n2096 http://dx.doi.org/10.1136/bmj.n2096 Published: 24 August 2021

\title{
Covid-19: FDA approves Pfizer-BioNTech vaccine in record time
}

\section{Janice Hopkins Tanne}

The US Food and Drug Administration has granted full approval to the two dose Pfizer-BioNTech vaccine to protect against covid-19 for people aged 16 and above. The vaccine's previous emergency use authorisation will continue for 12 to 15 year olds. ${ }^{1}$

President Biden used the approval to urge hesitant Americans to get vaccinated and called on businesses and local leaders to require employees to get vaccinated. A June poll showed that $31 \%$ of unvaccinated people would be more likely to accept the vaccine if it had full FDA approval. ${ }^{2}$

In a speech at the White House on 23 August Biden said, "If you're one of the millions of Americans who said they will not get the shot until it has full and final approval of the FDA ... The moment you've been waiting for is here, and it's time for you to go get your vaccination and get it today. Across the country, virtually all of the covid-19 hospitalisations and deaths continue to be among the unvaccinated."3

Biden said that he had "imposed vaccination requirements that will reach millions of Americans," such as federal government employees. Now he was calling on companies in the private sector "to step up with vaccine requirements that'll reach millions more people.” The Defense Department said that it was moving towards requiring vaccination of members of the armed forces.

The American Medical Association, the American Hospital Association, and the American Nurses Association praised the FDA approval, saying that covid-19 vaccines had already protected more than 100 million Americans. "This vaccine is safe, it prevents severe covid-19, and it will save your life," the organisations said in a joint press release. ${ }^{4}$

\section{High standards}

The vaccine has been used under emergency authorisation since December 2020, with Pfizer applying for full approval on 7 May 2021 and approval being granted in under four months, the fastest time in FDA history.

Private companies and local leaders making the vaccine mandatory may prove more effective and acceptable to vaccine hesitant Americans than calls by the government for vaccine requirements. Already several major companies and many schools, colleges, universities, and big cities have issued vaccine requirements for employment or attendance at museums, theatres, and restaurants. FDA approval may reassure people who are reluctant to get the vaccine.

Anthony Fauci, director of the National Institute of Allergy and Infectious Diseases, told the national television programme PBS Newshour that the FDA was "the gold standard of regulatory agencies throughout the world ... They had a voluminous amount of data. They worked double time fast. They just did not cut any corners. They examined every bit of it [the data]."5

Janet Woodcock, acting FDA commissioner, emphasised that the vaccine "meets the high standards for safety, effectiveness, and manufacturing quality [that] the FDA requires of an approved product. Millions of people have already safely received covid-19 vaccines." ${ }^{1}$

\section{Safety data}

To assess effectiveness the FDA analysed data from about 20 ooo people who received the vaccine and 20 ooo who received a placebo. To assess safety it evaluated data from about 22000 people who received the vaccine and 22000 who received a placebo. The clinical trials showed that the vaccine was $91 \%$ effective in preventing covid-19 disease.

In addition, the FDA evaluated safety data relating to myocarditis and pericarditis, which showed an increased risk particularly within seven days after the second vaccine dose. This risk was higher in men under 40 than in women and older men, and it was highest in young men aged 12 to 17 . The FDA requires Pfizer to conduct post-marketing studies to further assess the risks, and although not required, Pfizer plans further post-marketing safety studies, including in women who received the vaccine during pregnancy and their infants.

Last week the FDA was criticised for announcing that it would not hold a formal advisory committee meeting to discuss data supporting the approval, after saying last year that it was committed to using such a meeting "to ensure deliberations about authorisation or licensure are transparent for the public." 6 The agency told The BMJ it did not believe that a meeting was necessary on this occasion.

Pfizer-BioNTech will market the vaccine as Comirnaty in the United States, and its US prescribing information is available online. ${ }^{7}$ Pfizer plans to manufacture three billion doses this year and to deliver two billion globally, while the US has committed to buying one billion doses, half of which it plans to donate internationally. Pfizer raised its expected sales of Comirnaty this year to $\$ 33.5 \mathrm{bn}$ (£24.4bn; €28.6bn). ${ }^{8}$

Moderna and Johnson \& Johnson have also applied for full approval of their vaccines. Clinical trials of all three of these vaccines are continuing in younger age groups.

See also: Does the FDA think these data justify the first full approval of a covid-19 vaccine? (BMJ Opinion, 23 Aug 2021;

https://blogs.bmj.com/bmj/2021/08/23/does-the-fda-think-these-data-justifythe-first-full-approval-of-a-covid-19-vaccine/) 
1 US Food and Drug Administration. FDA approves first covid-19 vaccine. 23 Aug 2021. https://www.fda.gov/news-events/press-announcements/fda-approves-first-covid-19-vaccine

2 Kaiser Family Foundation. KFF covid-19 vaccine monitor: June 2021. 30 Jun 2021. https://www.kff.org/coronavirus-covid-19/poll-finding/kff-covid-19-vaccine-monitor-june-2021/

3 White House. Remarks by President Biden on the covid-19 response and the vaccination program 23 Aug 2021. https://www.whitehouse.gov/briefing-room/speeches-remarks/2021/08/23/remarksby-president-biden-on-the-covid-19-response-and-the-vaccination-program-7/

4 American Medical Association. AMA, AHA, ANA applaud FDA full approval of Pfizer covid-19 vaccine, urge all to get vaccinated. 23 Aug 2021. https://www.aha.org/press-releases/2021-0823-aha-ama-ana-applaud-fda-full-approval-pfizer-covid-19-vaccine-urge-all

5 Dr Fauci on Pfizer vaccine's FDA approval, approving Moderna and Johnson \& Johnson shots. PBS Newshour2021 Aug 23. https://www.pbs.org/newshour/show/dr-fauci-on-pfizer-vaccinesfda-approval-approving-moderna-and-johnson-johnson-shots

6 lacobucci G. Covid-19: FDA set to grant full approval to Pfizer vaccine without public discussion of data. BMJ2021;374:n2086. doi: 10.1136/bmj.n2086 pmid: 34417195

7 Pfizer-BioNTech prescribing information. Updated Aug 2021. https://labeling.pfizer.com/ShowLabeling.aspx?id=15623

8 Higgins-Dunn N. Pfizer, BioNTech score FDA's first full covid-19 vaccine nod, quickly triggering stricter mandates. Fiercepharma 2021 Aug 23. https://www.fiercepharma.com/pharma/pfizerand-biontech-s-comirnaty-scores-fda-s-first-full-covid-19-vaccine-approval

This article is made freely available for use in accordance with BMI's website terms and conditions for the duration of the covid-19 pandemic or until otherwise determined by BMJ. You may use, download and print the article for any lawful, non-commercial purpose (including text and data mining) provided that all copyright notices and trade marks are retained. 